\title{
Measurement of personality and attitude: applications to clinical research
}

\author{
ISAAC MARKS \\ M.D., D.P.M. \\ Senior Lecturer, Institute of Psychiatry, Maudsley Hospital, London, S.E.5
}

Changes in personality and attitudes are a salient aspect of many psychiatric disorders. It is therefore important for psychiatrists to have accurate measures of personality functions and relevant attitudes. Over the last 50 years many measures of personality have been developed, mainly by psychologists, but until recently few of these had much clinical utility. Most measures in this area were devised to explore normal personality function, or to test socio-psychological theories, or for special purposes like vocational guidance. In the last few years more attention has been paid to clinical application of these measures so that instruments are now emerging which hold promise for psychiatric research, although none of these instruments is yet suitable for routine clinical work.

At first glance there is a daunting array of measures with strange names and varied theoretical premises. In fact many of them are constructed on similar principles and overlap considerably. The most important point for an initiate is whether a particular measure is relevant to the clinical issue in question, and if it is, whether that measure is reliable, valid and sensitive to clinical change.

The question of relevance is crucial. The term 'personality' denotes the characteristic ways in which an individual behaves in a wide variety of situations. It includes the way in which he gets along with his family, friends and workmates, his appearance, abilities, motives, and ambitions, his emotional reactivity, whether he is generous or mean, dominant or submissive, energetic or apathetic, hysterical or hypochondriacal, cheerful or depressed. Furthermore, it includes his psychiatric complaints. It is clearly unrealistic to expect any single measure to encompass all these facets, or to expect all these facets to be relevant to a given psychiatric disturbance. The clinician has to select those aspects which are germane to his clinical interests. If he is interested in an individual's ability to get on with his peers he will want a measure of social adjustment and will not be particularly interested in measures of creativity or sexual satisfaction.

Many personality measures have tried to reduce the multiple characteristics of personality into a few dimensions, but so far none has succeeded. As a noted text commented '[personality inventories] remain fallible instruments and their improvement is one of the pressing tasks facing psychology' (Hilgard, 1962). If one has more limited aims and tries not to encompass the total personality but to follow a given sector of personality function instead then certain measures become less fallible and indeed have some clinical use.

Attitude is an aspect of personality, and may be defined as an orientation and a readiness to respond toward or away from some object, concept or situation. Attitudes involve emotional, motivational and intellectual aspects, i.e. attitudes involve feelings about an object or situation, an action tendency toward it and certain beliefs about it. The degree of favourableness or unfavourableness of an attitude to an object is called the valency of that attitude. Attitudes show some consistency in the feelings, beliefs and overt actions called forth by the object of those attitudes. Knowing an individual's attitude to a situation will give some clue to the way that individual will behave in the situation concerned, though there are many variables in addition to attitude which determine whether or not an individual will act in a given situation. In other words, attitude is only one intervening variable between feeling and overt behaviour. In psychiatric work attitude is best used together with other measures including clinical assessment.

Enduring attitudes develop through many learning experiences related to other people. As attitudes become interwoven with experience they develop into abiding personality characteristics, so that an individual's attitudes to certain situations, e.g. religion, are an aspect of his per- 
sonality. Measurement of attitude therefore involves measuring a facet of personality.

Hundreds of personality measures exist, most of which are personality inventories and projective techniques. A comprehensive survey is available in the Mental Measurements Year Book (Buros, 1965). The principles of psychological test construction are given by Anastasi (1961), and Vernon (1964) supplies a useful critique of personality measures. This paper will only consider those instruments which are in common use, with illustrations of some clinical applications.

A brief explanation is necessary of the type of scale most used in psychological testing, including measures of personality and attitude. Scales in general can be divided into three types; ratio, interval and ordinal scales.

Ratio scales start with a true zero and have equal intervals between successive units. An example of a ratio scale is our measure of length, where a rod $10 \mathrm{~cm}$ in length is twice as long as another rod $5 \mathrm{~cm}$ in length.

Interval scales, on the other hand, have an arbitrary zero though they still have equal intervals between successive units. Examples of this are our Centigrade and Fahrenheit measures of temperature. An object at a temperature of $60^{\circ} \mathrm{C}$ is not twice as hot as an object at a temperature of $30^{\circ} \mathrm{C}$.

The third type of scale-ordinal scales-has neither a true zero nor truly equal intervals between successive units, successive items merely being placed in their order of size. Many psychological tests are of this variety. An example would be a measure of 'neuroticism' which simply tells us how 'neurotic' an individual is with regard to a standard population. It has no true zero and does not allow us to say that an individual with a score of, say, 40 on a given test is twice as 'neurotic' as someone with a score of 20. Furthermore, the interval between a score of 15 and 20 is not necessarily equivalent to that between 35 and 40 .

\section{Personality inventories}

Most personality inventories are self-report questionnaires or card sorts. In a typical inventory the subject answers a list of up to 500 questions with a simple 'yes' or 'no' or 'cannot say'. Alternatively, the questions may be printed on cards, and the patient answers by sorting the cards into the three categories 'yes', 'no' or 'cannot say'. Another way would be for the patient to make a choice between pairs of statements, lists of these pairs being printed together on a sheet of paper or separately on cards, one pair of statements per card.

It is obvious that the utility of a personality inventory depends in the first place on the statements which go to make up that inventory. The items in an inventory are usually chosen intuitively for their relevance to personality or clinical problems. After empirical testing the most useful items are retained from a large initial pool of statements. Many inventories contain similar questions, e.g. the Taylor Manifest Anxiety Scale (Taylor, 1953) is derived from part of the M.M.P.I. (Hathaway \& Meehl, 1951), and the Maudsley and Eysenck Personality Inventories (Eysenck, 1959; Eysenck \& Eysenck, 1964), the Cornell Medical Index (Brodman et al., 1949) and the Tavistock Self Assessment Inventory (Dixon, de Monchaux \& Sandler, 1957a, b) share many items, and in fact the scores for these questionnaires correlate highly with one another (Marks, 1967).

1. The M.M.P.I. (Minnesota Multiphasic Personality Inventory) (Hathaway \& Meehl, 1951) is probably the most widely used of all inventories, especially in North America. It was originally developed as a clinical instrument to measure the characteristic traits of disabling. psychological disorders. It consists of 550 state ments which have to be answered 'true', 'false' or 'cannot say'. The statements cover many areas from physical health to neurological disorders and political and social attitudes. Two examples of statements are 'I believe I am being plotted against' and 'I am worried about sex matters'.

The 550 statements fall into ten clinical groups with labels like 'depression', 'hysteria' and 'paranoid'. There are also four groups of items which check for carelessness, malingering and similar problems. Each group of items has been worked out empirically on groups of patients diagnosed as depressive, hysteric, paranoid, etc. The scores on these items are also known for control populations. The test results are plotted as a profile which can be compared with that obtained in normal people and with different types of patients. It is also possible to see whether the profile changes after a given treatment (e.g. Brill et al., 1964).

The disadvantage of the M.M.P.I. is that it is quite cumbersome, and that the original grouping of items was made intuitively and may not reflect the most natural groups which occur in practice. Finally, the M.M.P.I. does not assess personality function within the normal range of adjustment.

2. M.P.I (Maudsley Personality Inventory) (Eysenck, 1959 ; Eysenck \& Eysenck, 1964). 
This is one of the most widely used inventories in Britain and has recently been revised and renamed the E.P.I. (Eysenck Personality Inventory). There are two alternative forms of forty-eight questions and each question has to be answered 'yes' or 'no'. These questions were based on an analysis of 250 questions appearing in other well-known inventories. The forty-eight questions fall into two groups named extraversion (E) and neuroticism (N) and the result is reported in terms of an extraversion and neuroticism score. It is claimed that these represent fundamental dimensions of personality but in fact these two dimensions can be broken down into further categories depending upon the method of analysis employed (Eysenck, Hendrickson \& Eysenck, 1968). The usual scores are known for groups of normal subjects and for patients with certain abnormalities. The scores remain reasonably stable from one occasion to the next and the test is easy to give and score.

The M.P.I. has been helpful in following the changes in some patients. It is dubious, however, whether the $\mathbf{N}$ score is more valuable than similar instruments like the Cornell Medical Index and the Taylor Manifest Anxiety Scale with which the $\mathbf{N}$ score correlates highly, or whether the $E$ score is more valuable than other measures of sociability.

An example of a study in which the M.P.I. has been useful comes from Levinson \& Meyer (1965) who studied the changes in two groups of neurotic patients after modified leucotomy. Fig. 1 shows the change in scores before and after leucotomy. After operation the patients became more 'extraverted' (i.e. sociable) and less 'neurotic' (i.e. had fewer complaints), and this change agreed with the overall condition assessed clinically. It is noteworthy that the change in the Taylor scale (marked 'Anxiety' (MAS)) runs parallel to that in the $\mathbf{N}$ score.

The M.P.I. has also been useful in showing how the partners in a marriage come to resemble one another more as the years go by (Kreitman, 1964), and in studying psychiatric morbidity in a new town (Hare \& Shaw, 1965).

3. Cornell Medical Index (C.M.I.) (Brodman et al., 1949).

This instrument is not usually called a personality inventory but albeit by accident it serves as one and is widely used in psychiatric work. The C.M.I. is a list of 195 questions about physical and mental health which was designed as a rapid scan of patients' complaints before they saw a doctor. About half the items (sections A-L) concern physical symptoms, and the other half (sections $M-R$ ) deal with psycho- logical problems. The total score is a measure of how many complaints the patient has. The score on sections $\mathbf{M}-\mathbf{R}$ correlates highly with neuroticism of the M.P.I. and anxiety of the Taylor scale. The C.M.I. has been useful in identifying patients with multiple complaints who are likely to seek medical help and has been used extensively in epidemiological and clinical work (e.g. Shepherd et al., 1966, Ingram, Evans \& Oppenheim, 1963 ; Brown \& Fry, 1962 ; Kreitman, 1964). Usual scores are available for normal subjects and for groups of patients with different abnormalities. The scores are reasonably stable from one occasion to the next. The test takes no account of the tendency for patients to show a response set, i.e. to answer 'yes' or 'no' repeatedly to any questions regardless of their content. The questionnaire also gives no indication about the normal aspects of a patient's personality.

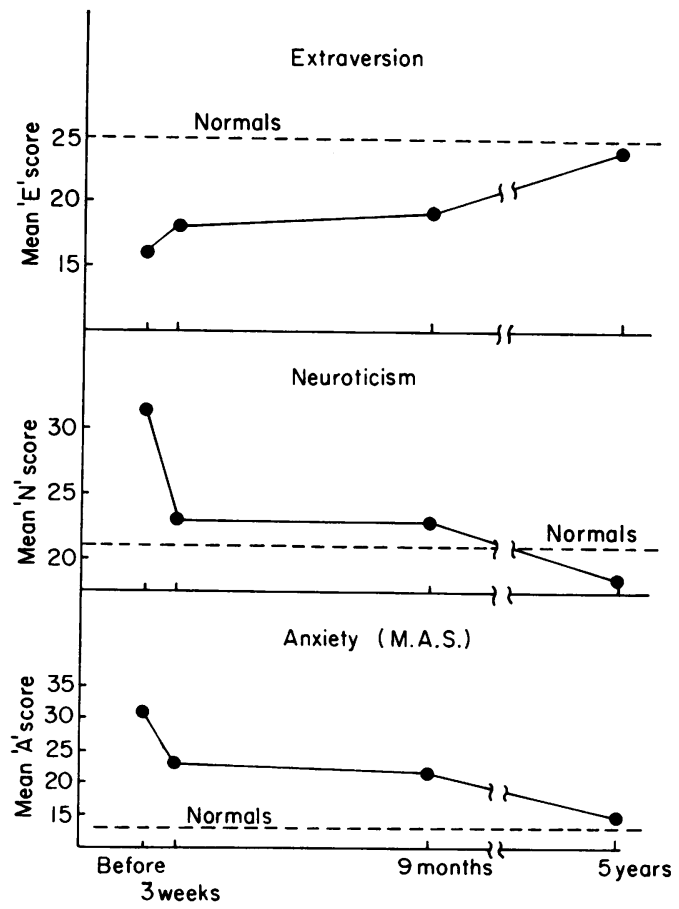

FIG. 1. Effect of leucotomy in 207 patients. Note change in scores of 'extraversion' and 'neuroticism' on the Maudsley Personality Inventory and in scores on the Taylor Manifest Anxiety Scale (based on data of Levinson \& Meyer, 1965).

Other well-known personality inventories include the Edwards Personal Preference Schedule (Edwards, 1953) which appraises motivational dispositions, and Cattell's 16F (personality fac- 
tor) Questionnaire (Cattell, 1957, 1965) which scans sixteen areas of personality function, including aspects of anxiety.

\section{Comparison of personality and intelligence tests}

On the whole, personality inventories have not fulfilled the earlier promise with which they were regarded after intelligence tests had proved their usefulness in the first decades of this century. In fact there are major differences between intelligence and personality tests. Intelligence tests are tests of ability which seek to ascertain an individual's maximum performance. Any single item has a correct answer and patients usually strive to perform to their best ability. Faking a wrong answer results in an incorrect answer and a lower intelligence score, not a higher one. Faking is not generally a problem except in those rare instances where intelligent subjects wish to conceal their ability. In contrast, personality inventories seek the characteristic performance rather than a best one and no single item has an independent correct answer. Consistently wrong answers can therefore result in false negatives and false positives, i.e. normals may simulate disturbance and disturbed people can conceal their problems and pass as normal.

Another difference between intelligence and personality tests is that intelligence tests have clearer criteria by which they can be validated. They are tests of ability and results can be compared with scholastic performance. Personality inventories, on the other hand, have less clear-cut criteria by which they can be evaluated. This is partly because personality is more complex than intelligence, and partly because we lack external criteria for personality performance of the sort we have for intelligence tests in the form of scholastic attainments.

\section{Projective techniques}

Patients filling in personality inventories can only reply according to fixed alternatives. Projective tests were devised to allow the patient to answer more freely by interpreting ambiguous items such as ink-blots and poorly structured pictures, or by creative activities in finger painting and drawing. It is assumed that the patient's interpretations will reflect his inner feelings, and that the freer situation will allow the patient to project his personality through the test. The principle employed is that devised by Hamlet: 'the play's the thing wherein I'll catch the conscience of the king'.

Projective techniques are widely employed. One of the best known is the Rorschach inkblot test in which the patient gives his associations to a series of complex inkblots. Another commonly used method is the Thematic Apperception Test (TAT) in which the patient tells stories about a series of pictures which he is shown; the stories tend to form round basic themes which reflect various aspects of his personality. The Sentence Completion Test is self explanatory. For children, structured forms of doll-play are used as projective methods.

Projective techniques are an ingenious way to reveal hidden aspects of personality in certain cases. However, projective tests have fulfilled their earlier promise even less than personality inventories because of the difficulty in getting dependable scores and interpretations. Recent attempts have been made to improve projective methods (e.g. Holtzman et al., 1961). Despite such efforts Munn (1965) noted that 'until (projective methods) are more standardized, quantified and validated they will be of limited usefulness in personality research'. In a detailed critique of projective methods Zubin, Eron \& Schumer (1965) came to the same conclusion. Zubin (1967) suggested that more useful information is obtained from clinical interviews carried out in a systematic structured manner.

\section{Other measures of personality}

1. Kelly's Repertory Grid (Kelly, 1955).

This is a card-sorting method which allows a patient to reveal his personality by the way in which he judges a number of elements, e.g. people, objects or emotions on a series of constructs which are usually a pair of contrasting adjectives. Constructs can be either supplied to the subject or elicited from him. Eliciting is achieved by presenting the patient with three elements (e.g. three well-known people) and asking the patient to name some way in which two of the people are alike and thereby different from the third person. The patient might respond by saying that two of the people are intelligent but the third is stupid. One would then infer that the construct 'intelligent-stupid' was relevant for the patient in making judgements about his world. In this way a series of constructs can be elicited and the patient can then rate each element given to him on the series of constructs he has produced. One can then study the patient's ratings of the elements and constructs, and the relations among them, by special statistical analysis. This allows one to make useful inferences about the patient's way of viewing his world.

The technique is particularly useful when 
working with an individual patient. It is quite time-consuming and is rather cumbersome for use in a group of subjects. It has been used amongst other things as a measure of transference (Crisp, 1964), i.e. of the patient's feelings about the therapist, and this transference measure has then been related to clinical changes in patients with writer's cramp (Crisp \& Moldofsky, 1965). The repertory grid method is related to another technique which will be discussed below, viz. the semantic differential. A clear exposition of repertory grid procedure has been given by Bannister (1965) and computer programs now simplify the analysis of results (Slater, 1965).

2. Shapiro's Personal Questionnaire (Shapiro, 1961, 1963)

This is a card-sorting test which allows a patient to rate his symptoms repeatedly and reliably thus allowing detailed study of the changes during treatment. It is quite time-consuming and so is suitable only for intensive individual case studies. Fig. 2 shows the change in three symptoms in one case during two different treatments, viz. ECT and leucotomy. Each symptom was rated on a Personal Questionnaire card sort. The differential effect of the two treatments is obvious. This technique is useful for studying detailed changes in individual cases, though it is quite possible that simpler scales would serve just as well.

\section{3. $Q$ sort technique (Stephenson, 1953)}

This technique is based on a principle similar to that of the repertory grid and semantic differential, and has to some extent been replaced by them. A review of its status was given by Wittenborn (1961). It has been useful for individual case studies in psychotherapy and personality research.

\section{Attitude scales}

Attitude scales are constructed on lines similar to personality inventories except that they measure responses to a more limited variety of situations, and tend to be scored in terms of favourableness or unfavourableness. There are several types of attitude scale, and a good introductory discussion of these is to be found in Krech, Crutchfield \& Ballachey (1962) and Hilgard (1962).

Well-known attitudes scales include the Thurstone Scales (Thurstone \& Chave, 1929), Likert Scales (Likert, 1932), and Guttman's Scalogram (Guttmann, 1950). Thurstone Scales are an assembly of statements concerning a topic some of which are mildly favourable and unfavour- able, others of which are strongly favourable and unfavourable. These statements can be ranked in order of favourableness. Subjects are asked which statements they can endorse and the attitude score corresponds to the average scale position of the items he has endorsed. On the Likert Scales a given topic is rated on a scale with the five points 'strongly approve', 'approve', 'undecided', 'disapprove', 'strongly disapprove'. Results on Likert scales agree with Thurstone scales in discriminating between those people who hold favourable and those who hold unfavourable attitudes to a given issue (Hilgard, 1962).

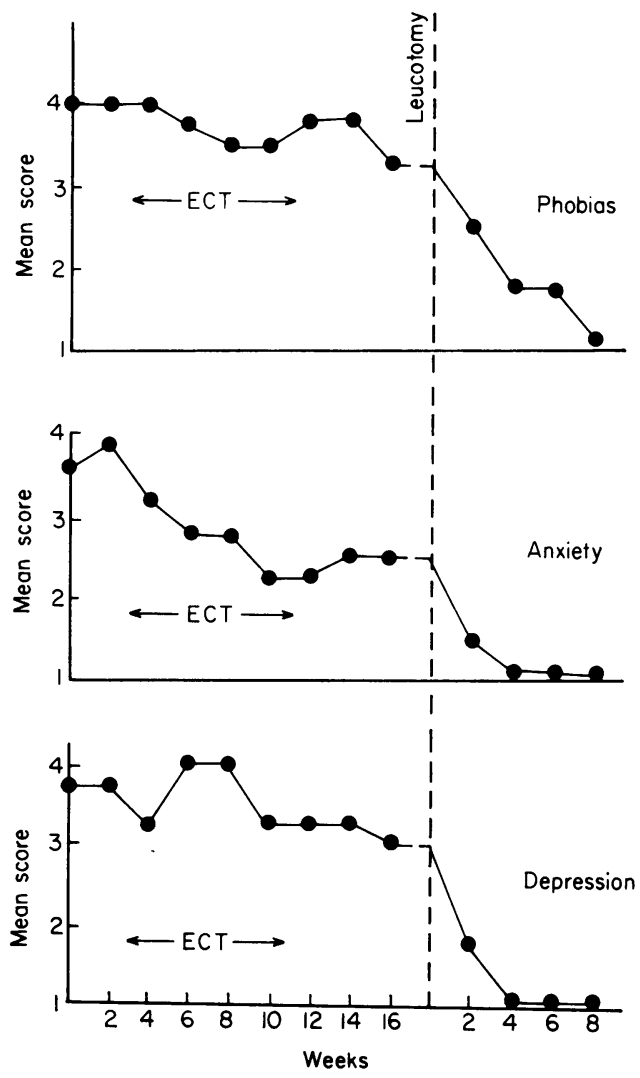

FIG. 2. Personal Questionnaire Scores before and after leucotomy in one patient (based on unpublished data of M. B. Shapiro).

Guttman's Scalogram seeks 'pure' scales along a single dimension. Items are arranged in a way which is increasingly favourable from the first to the tenth item and if an individual marks, say, item 4 favourably then all items above that will be rated favourably. 
A host of attitude scales has been constructed to measure attitudes to a great number of situations, for example, ethnic prejudice (Bogardus, 1925), masculinity and so on. Many of these are to be found in the Mental Measurements Year Book (Buros, 1965). The value of each measure will depend partly on its relevance to the problem in hand. A measure of prejudice, for example, is not of much help in a study of the masculinity of a patient's personality.

Attitude scales have a more limited aim than most measures of personality and have been rather more useful in a clinical setting. One drawback which has not been overcome, however, is that sophisticated observers could fake their replies to produce a spurious picture if they wished. In practice this rarely happens but for this reason attitude scales, like personality measures, should not be used alone in clinical work but rather should be used with other evidence from clinical sources. Just as in clinical work one prefers to make decisions on the basis of consistent evidence from many sources rather than on the basis of a single sign or symptom, so too in the use of attitude measures one is concerned with consistency of response and the way replies tally with other evidence.

\section{Semantic differential}

This is a method which was designed by Osgood (Osgood, Suci \& Tannenbaum, 1957; Osgood, 1962) to measure the meaning of concepts in a reliable and scorable fashion. In recent years the semantic differential technique has also been used increasingly to measure attitude and is now the most widely used instrument in psychiatric work for this purpose. Because of its utility it deserves detailed description. The principle is simple: patients are asked to rate concepts on a series of bi-polar seven point adjectival scales. A typical form might be as follows:

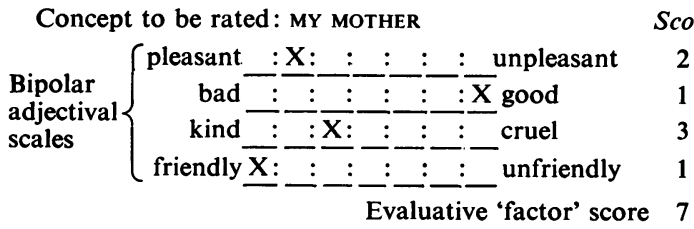

The scales are arranged so that the same pole of the scale sometimes appears on the left and sometimes on the right hand margin of the page to avoid the patients developing a response set. If one wishes the patient to rate twenty concepts on nine scales one would prepare a 20page booklet with a separate concept written at the top of each page and with the same nine scales appearing below the concept on every page.

Osgood originally found that of all the possible adjectival scales one could use to measure meaning most scales fell into three groups or 'factors' which he called evaluation (e.g. pleasant unpleasant, good-bad), potency (e.g. strongweak, powerful-helpless) and activity (e.g. activepassive, fast-slow). Subsequent workers have shown that only an evaluative factor is used regularly in judging a wide variety of situations and that the other two factors are not always employed. Evaluative scales are used to judge many situations and in fact give a useful measure of attitude valency, i.e. whether a patient is favourably or unfavourably disposed to a given situation (Krech et al., 1962).

Semantic differential measures methods have proved their usefulness in psychiatric work where attitude is relevant to the research problem. There are many examples of psychiatric applications. In one study group, obsessive-compulsive and psychopath in-patients could be differentiated from one another and from normal subjects by their meanings of concepts like 'myself', 'my father' and 'my mother' (Marks, $1965,1966)$ on evaluative scales. In another study (Marks \& Gelder, 1967) changes in sexual deviance could be followed during treatment byco the patient rating concepts related to his deviance on evaluative scales. Fig. 3 (B and C) shows the way in which a transvestite's attitude to several deviant concepts became unfavourable as aversion (electric shocks) was given while he wore different garments in turn, first brassieres then corsets and panties. Before this, attitudes had been unchanged after the patient had spent his first 3 days in hospital without shocks (Fig. 3A). Only deviant concepts became unfavourable by the end of treatment, and other concepts like 'my mother' and 'sexual intercourse' remained favourable on discharge (Fig. 3D). The selective change in attitude was accompanied by selective diminution in erections, and paralleled clinical improvement. When relapse occurred after discharge, this clinical change too was mirrored by a change in attitudes, which reverted back to their original orientation (Fig. 3E).

Fresh scales can be constructed when they are relevant to the research problem. For example a series of sex scales (e.g. seductive-repulsive, erotic-frigid) has proved useful when added to evaluative scales for the assessment of progress during treatment of sexual deviations (Marks \& Sartorius, 1968). The semantic differential technique can also be used as a repertory grid with 
the concepts being the elements and the scales being the constructs in Kelly's terminology (e.g. Marks \& Sartorius, 1968).

Provided one is careful to tailor the concepts and scales to one's research question and checks are made that the scale-scores cluster together to form genuine factors then the semantic differential is a useful and versatile instrument to measure attitudes in psychiatric work.

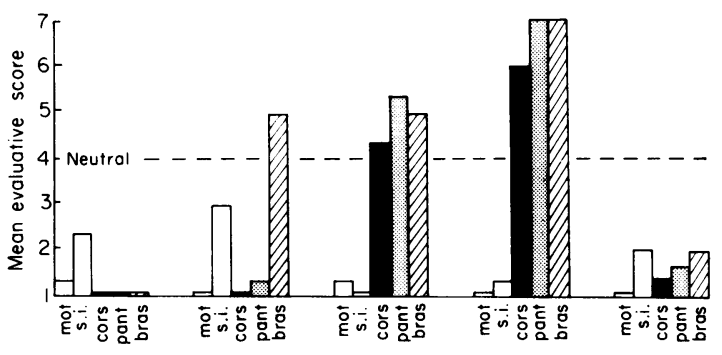

A

E

FIG. 3. Selective attitude change in a transvestite following selective aversion treatment (taken from Marks \& Gelder, 1967). Attitude was measured on evaluative scales of the semantic differential: $1=$ good, friendly, approachable; 7 = bad, unfriendly, distant. A, 3 days in hospital without shocks; B, 1 day of shocks to brassieres; $C, 2$ days of shocks to corsets and panties; $D, 11$ days of shocks to all garments; E, 5 weeks follow-up, gradual clinical relapse. mot $=$ mother, $\mathbf{s . i}$. $=$ sexual intercourse, cors $=$ corsets, pant $=$ panties, bras $=$ brassieres .

\section{Psychiatric rating scales}

For psychiatrists an important aspect of personality is a patient's social adjustment and the degree with which he suffers from a wide variety of abnormal symptoms. These are usually obtained by a detailed clinical interview with the patient and independent observers. However, interviews are difficult to score, therefore many rating scales have been developed to rate patients' symptoms and social adjustment in a manner which allows the results to be treated statistically. Among the earlier scales to be used were those of Wittenborn (1955) and Miles, Barrabee \&. Finesinger (1951).

Frank et al. (1963) successfully followed the progress of patients on a Discomfort Scale (Parloff, Kelman \& Frank, 1954 ; Kelman \& Parloff, 1957) and the Hildreth Feeling and Attitude Scales (Hildreth, 1946). Gelder \& Marks (1966) and Gelder, Marks \& Wolff (1967) found the modified scales of Miles et al. (1951) useful in assessing the treatment of phobic patients.

Among the most sophisticated clinical scales are those of Katz and of Lorr. The Katz adjustment scales (Katz \& Lyerly, 1963) are designed to assess different aspects of the patient's functioning in the community from the points of view of close relatives and the patient. Separate scales were designed for the relative and for the patient. The scales involve reports of the patient's symptoms, social behaviour, home activities and free-time activities. The derived scores permit estimates of his adjustment in the clinical, social and personal areas.

On the Lorr scales (Lorr et al., 1962, 1963, 1966) the clinician rates patients in a clinical interview on seventy-five scales. These scales fall into ten groups and ten scores result from the rating to produce a ten-element profile. By statistical analysis profiles can be divided into mutually exclusive subgroups of similar profiles or types. The scales can be used to classify patients and to follow their progress in treatment. As Zubin (1967) noted, this type of scale attempts an objective translation of what the great descriptive psychiatrists, Kraepelin, Bleuler and Meyer sought to do intuitively. It is still too early to know the limitations of scales such as those of Katz and of Lorr but they are among the most interesting clinical scales devised so far.

Other scales are available to follow more limited aspects of patient function, such as the Clyde Mood Scale (Clyde, 1963) which is helpful in obtaining repeated self-reports in changes of mood.

\section{Conclusion}

Personality and attitude measures have their uses and facilitate more sophisticated psychiatric research than is possible without them. These measures are an aid to the clinician and in no way replace him-they only try to apply clinical judgment in a measurable way. As Meehl (1954) concluded in an excellent review of this problem, clinical and actuarial methods each have their role in clinical research.

\section{Appendix}

\section{Suggestions for further reading}

For a general discussion of the value of clinical versus actuarial prediction see Meehl (1954). Detailed appraisal of most psychological tests, with comprehensive references, appears in the Sixth Mental Measurements Year Book (Buros, 1965). A good introductory discussion of personality and attitude measures is given by Hilgard (1962). Krech et al. (1962) give a valuable review of attitude measures. Principles of psychological test construction are detailed by Anastasi (1961), and reviewed by Vernon (1954). Psychiatric rating scales are well reviewed in Lorr et 
al. (1963). An introduction to Kelly's Repertory Grid is provided by Bannister (1965) and to the semantic differential by Marks $(1965,1966)$.

\section{Acknowledgments}

Many thanks are due to Dr M. Crowe, DrS. Rachman and Mr A. Mathews for their valuable comments on the manuscript.

\section{References}

Anastasi, A (1961) Psychological Testing. MacMillan, New York.

BANNISTER, D (1965) The rationale and clinical relevance of repertory grid technique. Brit. J. Psychiat. 111, 977.

Bogardus, E S (1925) Measuring social distance. J. appl. Sociol. 9, 299 (cited in Krech et al., 1962).

Brill, N.Q., Koegler, R.R., Epstein, L.J. \& Forgy, E.W. (1964) Controlled study of psychiatric outpatient treatment. Arch. gen. Psychiat. 10, 581.

Brodman, K., Erdmann, A.J., Lorge, I., Wolff, H.G. \& Broadbent, T.H. (1949) The Cornell Medical Index-An adjunct to medical interview. J. Amer. med. Ass. 140, 530.

Brown, A.C. \& FrY, J. (1962) The Cornell Medical Index Health Questionnaire in the identification of neurotic patients in general practice. J. psychosom. Res. 6, 185.

Buros, O.K. (1965) The Sixth Mental Measurements Year Book. Gryphon Press, Highland Park, New Jersey.

Cattell, R.B. (1957) Sixteen Personality Factor Questionnaire (Rev. Ed.). Institute for Personality and Ability Testing, Champaign, Ill.

Cattell, R.B. (1965) The Scientific Analysis of Personality. Pelican Books No. A712.

Clyde, D.J. (1963) Manual for the Clyde Mood Scale. Coral Gables, Florida. Biometric Laboratory, University of Miami.

CRISP, A.H. (1964) An attempt to measure an aspect of transference. Brit. J. med. Psychol. 37, 17.

CRISP, A.H. \& MoldofSKY, H. (1965) A psychosomatic study of writer's cramp. Brit. J. Psychiat. 111, 841.

DENT, J.K. (1966) A Bibliographic Index of Evaluation in Mental Health. Public Health Service Publication No. 1545. National Institute of Health, Bethesda, Md. 20014. (For sale by Superintendent of Documents, U.S. Govt. Printing Office, Washington, D.C. 20402-60 cents.)

Dixon, J.J., De Monchaux, C. \& SANDler, J. (1957a) Patterns of anxiety: an analysis of social anxieties. Brit. J. med. Psychol. 30, 107.

Dixon, J.J., De Monchaux, C. \& Sandler, J. (1957b) Patterns of anxiety: the phobias. Brit. J. med. Psychol. 30, 34.

EDWARDS, A.L. (1953) Manual of Edwards Personal Preference Schedule. The Psychological Corporation, New York.

EySENCK, H.J. (1959) Manual of the Maudsley Personality Inventory. London.

EYSENCK, H.J. \& EYSENCK, S.B.G. (1964) Manual of the Eysenck Personality Inventory. London.

Eysenck, H.J., Hendrickson, A.E. \& Eysenck, S.B.G. (1968) A factor analytic study of personality structure. (In press).

Frank, J.D., NASh, E.H., Stone, A.R. \& Imber, S.D. (1963) Immediate and long-term symptomatic course of psychiatric outpatients. Amer. J. Psychiat. 120, 429.

Gelder, M.G. \& MARKS, I.M. (1966) Severe agoraphobia: a controlled prospective trial of behaviour therapy. Brit. $J$. Psychiat. 112, 309.

Gelder, M.G., Marks, I.M. \& Wolff, H.H. (1967) Desensitization and psychotherapy in the treatment of phobic states: a controlled inquiry. Brit. J. Psychiat. 113, 53.
GuttmanN, L. (1950) The basis for scalogram analysis. Stouffer, S.A. et al.: Measurement and Prediction, pp. 60-90. Princeton University Press. (Cited by Hilgard, 1962.)

HARE, E.H. \& Shaw, G.K. (1965) Mental Health on a New Housing Estate. Maudsley Monograph No. 12. Oxford University Press.

Hathaway, S.R. \& Meehl, P.E. (1951) An Atlas for the Minnesota Multiphasic Personality Inventory. Oxford University Press.

HiLDRETH, H.M. (1946) A battery of feeling and attitude scales for clinical use. J. clin. Psychol. 2, 214.

Hilgard, E.R. (1962) Introduction to Psychology. Methuen, London.

Holtzman, W.H., Thorpe, J.S., Swartz, J.D. \& Herrow, E.W. (1961) Inkblot Perception and Personality: Holtzman Inkblot Technique. University of Texas Press. (Cited by Hilgard, 1962; Vernon, 1964.)

Ingram, P.W., Evans, G. \& OpPenheim, A.N. (1963) Right illac fossa pain in young women, with appendix on the Cornell Medical Index Questionnaire. Brit. med. J. ii, 149.

KATZ, M.M. \& LYeRLY, S.B. (1963) Methods for measuring adjustment and social behaviour in the community. Psychol. Repts, 13, 503.

Kelly, G.A. (1955) The Psychology of Personal Constructs. Norton, New York.

Kelman, H.C. \& Parloff, M.B. (1957). J. abnorm. Soc. Psychol. 54, 281.

Krech, D., CRutchfield, R.S. \& Ballachey, E.L. (1962) Individual in Society. A Textbook of Social Psychology. McGraw-Hill, London.

Kreitman, N. (1964) The patient's spouse. Brit. J. Psychiat. $110,159$.

Levinson, F. \& Meyer, V. (1965) Personality changes in relation to psychiatric status following orbital cortex undercutting. Brit. J. Psychiat. 111, 207.

LIKERT, R.A. (1932) A technique for the measurement of attitudes. Arch. Psychol., N.Y. 28, No. 194 (cited by Hilgard, 1962).

LORR, M., KLETT, C.J. \& MCNAIR, D.M. (1963) Syndromes of Psychosis. Pergamon Press, London.

LORR, M., KLETT, C.J. \& MCNAIR, D.M. (1966) Explorations in Typing Psychotics. Pergamon Press, London.

LORR, M., MCNAIR, D.M., KLETT, C.J. \& LASKY, J.J. (1962) Evidence of 10 psychotic syndromes. J. consult. Psychol. 26, 185.

LYERLY, S.B. \& ABBotT, P.S. Handbook of Psychiatric Rating Scales. U.S. Govt. Printing Office, Washington. NIMH, Bethesda, Maryland 20014.

Marks, I.M. (1965) Patterns of Meaning in Psychiatric Patients. Maudlsey Monograph No. 13. Oxford University Press.

MARKS, I.M. (1966) Semantic differential uses in psychiatric patients. Brit. J. Psychiat. 112, 945.

MARKS, I.M. (1967) Components and correlates in psychiatric questionnaires. Brit. J. med. Psychol. 40, 261.

MARKS, I.M. \& Gelder, M.G. (1967) Transvestism and fetishism: clinical and psychological changes during faradic aversion. Brit. J. Psychiat. 113, 711.

Marks, I.M. \& SARTorius, N. (1968) A contribution to the measurement of sexual attitude: The semantic differential as a measure of sexual attitude in sexual deviations. J. nerv. ment. Dis. 146. (In press).

Meehl, P.B. (1954) Clinical versus Statistical Prediction; A Theoretical Analysis and Review of the Evidence. Minneapolis.

Miles, H., Barrabee, E. \& Finesinger, J. (1951) Evaluation of psychotherapy: with a follow-up study of 62 cases of anxiety neurosis. Psychosom. Med. 13, 82.

Munn, N.L. (1965) The Evolution and Growth of Human Behaviour, 2nd edn. Harrap, London. 
OsGooD, C.E. (1962) The generality of affective meaning systems. Amer. Psychologist, 17, 10.

Osgood, C.E., Suci, G.J. \& Tannenbaum, P.H. (1957) The Measurement of Meaning. Illinois.

Parloff, M.B., Kelman, H.C. \& Frank, J.D. (1954) Comfort, effectiveness and self-awareness as criteria of improvement in psychotherapy. Amer. J. Psychiat. 111, 343.

SHAPIRO, M.B. (1961) A method of measuring psychological changes specific to the individual psychiatric patient. Brit. J. med. Psychol. 34, 151.

ShaPIRo, M.B. (1963) In: Methods of Psychiatric Research. An Introduction for Clinical Psychiatrics (Ed. by P. Sainsbury and N. Kreitman). Oxford University Press, London.

Shepherd, M., Cooper, B., Brown, A.C. \& Kalton, G. (1966) Psychiatric Illness in General Practice. Oxford University Press.

Slater, P. (1965) The use of the repertory grid technique in the individual case. Brit. J. Psychiat. 111, 965.
STEPHENSON, W. (1953) The Study of Behaviour. University of Chicago Press.

TAYLOR, J.A. (1953) A personality scale of manifest anxiety. J. abnorm. soc. Psychol. 48, 285.

Thurstone, L.L. \& Chave, E.J. (1929) The Measurement of Attitudes. University of Chicago Press. (Cited by Krech et al., 1962; Hilgard, 1962.)

VERnON, P.E. (1964) Personality Assessment: A Critical Survey. Methuen, London.

WITTENBORN, J.R. (1955) Wittenborn Psychiatric Rating Scales. Psychological Corporation, New York. (Cited by Lorr et al., 1963.)

WITTENBORN, J.R. (1961) Contributions and current status of methodology. Psychol. Bull. 58, 132.

ZuBIN, J. (1967) Classification of the behaviour disorders. Ann. Rev. Psychol. 18, 389.

Zubin, J., Eron, L.D. \& Schumer, F. (1965) An Experimental Approach to Projective Techniques. Wiley, New York. 